\title{
Tension pneumoperitoneum caused by rupture of intraabdominal soft tissue emphysema in a child supported with high-frequency oscillatory ventilation: a case report
}

\author{
Pussayaban Suwankeeree ${ }^{1}$, Sudarat Jungkraisri ${ }^{1}$, Paiboon Sookpotarom ${ }^{2^{*}}$ (D) and Paisarn Vejchapipat ${ }^{3}$
}

\begin{abstract}
Background: We reported a case with tension pneumoperitoneum while being on high-frequency oscillatory ventilation.

Case presentation: A 12-month-old Thai girl presented with acute respiratory distress syndrome, septic shock, and bacterial pneumonia. Although supported with mechanical ventilation, she still had severe hypoxia. She was then transitioned to high-frequency oscillatory ventilation. During a weaning period on day 7 , she developed left tension pneumothorax requiring intercostal drainage and a markedly large amount of pneumoperitoneum. In spite of a bedside abdominocentesis, her abdomen was still tense and her hemodynamics was unstable. Subsequently, to exclude hollow viscus perforation, diaphragmatic injury caused by intercostal drainage, or abdominal compartment syndrome, she was transferred for surgery. There was no intestinal perforation. Postoperatively, she was on oxygen therapy, on chest physical therapy, and kept hemodynamically stable until she had recovered.

Conclusion: A case of tension pneumoperitoneum probably caused by high-frequency oscillatory ventilation was reported. Awareness of this condition should be included in the differential diagnosis.
\end{abstract}

Keywords: Case report, Pneumoperitoneum, Emphysema, Pneumothorax, High-frequency oscillatory ventilation

\section{Introduction}

Pneumoperitoneum is generally caused by alimentary tract injury; however, pneumoperitoneum occasionally occurs as a rare presentation of barotrauma caused by ventilatory support. Most of the time, ventilator-related pneumoperitoneum can be safely treated by non-surgical means [1-6]. However, this therapeutic practice might not be implemented in all cases. We report a case with tension pneumoperitoneum while being on high-frequency oscillatory ventilation (HFOV).

* Correspondence: sookpotarom@yahoo.com

${ }^{2}$ Department of Surgery, Panyananthaphikkhu Chonprathan Medical Center,

Srinakharinwirot University, 222 Tiwanon Road, Pak Kret, Nonthaburi 11120,

Thailand

Full list of author information is available at the end of the article

\section{Patient information}

A female patient had a history of prematurity and primary abdominal repair for gastroschisis at birth. There was no genetic investigation with respect to the congenital anomalies. There were no other associated anomalies. Subsequently, she was adopted, reared, and cared for by caregivers at a children's center. The presentation of this reported case was the first episode of significant sickness in her life.

\section{Timeline}

\section{Prenatal history}

There was a lack of prenatal history.

(C) The Author(s). 2019 Open Access This article is distributed under the terms of the Creative Commons Attribution 4.0 International License (http://creativecommons.org/licenses/by/4.0/), which permits unrestricted use, distribution, and reproduction in any medium, provided you give appropriate credit to the original author(s) and the source, provide a link to the Creative Commons license, and indicate if changes were made. The Creative Commons Public Domain Dedication waiver (http://creativecommons.org/publicdomain/zero/1.0/) applies to the data made available in this article, unless otherwise stated. 


\section{Past illness}

She suffered from premature delivery with unknown actual gestation and gastroschisis at birth. She underwent primary abdominal closure and recovered uneventfully.

\section{Family and psychosocial history}

Because of the inability of the parents to rear their child, she was adopted to live in a children's center. She grew up well and this presentation was her first severe illness after the birth defects. There was no record of any interventions for any diseases in the past in her individual recorded file.

\section{Past history}

There was no medical record of any severe condition except some minor reports of upper respiratory tract infection.

\section{Presenting concerns}

She presented with signs and symptoms of acute respiratory distress syndrome (ARDS). Her clinical and laboratory findings which were consistent with bacterial pneumonia were construed as a primary cause of her severe illness. Consequently, she was supported with conventional ventilation and then switched to HFOV. After approximately a week of this support, unexpected events, that is, tension pneumothorax, pneumomediastinum, and pneumoperitoneum, occurred during a step of weaning.

\section{Diagnosis}

The diagnosis of primary pneumoperitoneum was made. However, following an abdominocentesis, she was still hemodynamically unstable.

\section{Intervention}

She was planned to be treated conservatively but she was then transferred to an operating room to exclude some surgical causes.

\section{Outcome}

After 20 days following surgery, she improved with oxygen therapy and chest physical therapy and uneventfully recovered. She also did well at 2-week follow-up.

\section{Case presentation}

A 12-month-old Thai girl was brought to our emergency department with high-grade fever, cough, and dyspnea. Her underlying disease was gastroschisis. She underwent primary abdominal closure at birth without complications.

Initial findings showed hypoxia, suprasternal and subcostal retraction, and crepitation on chest auscultation. According to these signs and symptoms, an initial provisional diagnosis of ARDS and septic shock had been made. All later investigations led to a diagnosis of severe bacterial pneumonia as a primary cause of ARDS. Upon examination, she had a body temperature of 39.0 ${ }^{\circ} \mathrm{C}$ with a heart rate of 170 beat per minute, a respiratory rate of 70 breaths per minute, an arterial blood pressure of $70 / 30 \mathrm{mmHg}$, and an oxygen saturation of $80 \%$. She looked drowsy with dyspnea. Mild cyanosis was seen on her lips. In addition to the abnormal sound found with stethoscope, we noticed that there was an abdominal paradoxical respiration. With respect to the conditions, she was intubated and supported with conventional mechanical ventilation $(\mathrm{CMV})$ at a mode of pressure control with positive end-expiratory pressure of $12 \mathrm{~mm}$ $\mathrm{H}_{2} \mathrm{O}$ and total inspiratory pressure of $30 \mathrm{mmHg}$. Despite the aggressive management, she still had severe hypoxia with a partial pressure of oxygen $\left(\mathrm{PaO}_{2}\right)$ of 82 mmHg. Consequently, she was transitioned to HFOV after 6 hours of CMV.

During the first 2 days of support with the maximum amplitude of HFOV and mean airway pressure of 32 $\mathrm{mmHg}$, she was able to be maintained with an oxygen saturation of over $88 \%$. Her condition seemed to uneventfully improve. During a weaning of mean airway pressure on day 7 of HFOV support, however, she developed an abrupt onset of inadequate ventilation and oxygenation. A radiography revealed left tension pneumothorax requiring intercostal drainage (ICD). A few hours after ICD, she suffered from a markedly distended abdomen with subcutaneous emphysema across her entire upper torso. Again, plain thoracoabdominal film showed pneumothorax with pneumomediastinum and a markedly large amount of pneumoperitoneum (Fig. 1). Her abdominal circumference suddenly increased from 40 to $50 \mathrm{~cm}$. She underwent a bedside abdominocentesis withdrawing approximately $1 \mathrm{~L}$ of air to release intraabdominal pressure, partially improving her hemodynamic instability. Her abdomen was still tense and her hemodynamics was unstable. Subsequently, to exclude diaphragmatic injuries secondary to ICD, hollow viscus perforation, or abdominal compartment syndrome as a primary cause, she was transferred for surgery. As she had financial support from the government, there was no financial challenge for her further management.

With an upper transverse incision, soft tissue emphysema was found in several places, including esophagogastric junction, mesenteric root, and terminal ileal serosa (Fig. 2). There was no fluid or blood intraabdominally. There was no intestinal perforation and the lesions were left in place. There were no lesions on both sides of her diaphragm. Therefore, the presence of intraabdominal air was certainly due to emphysematous leakage at the aforementioned sites not a passage through diaphragm or intestinal perforation. There was 


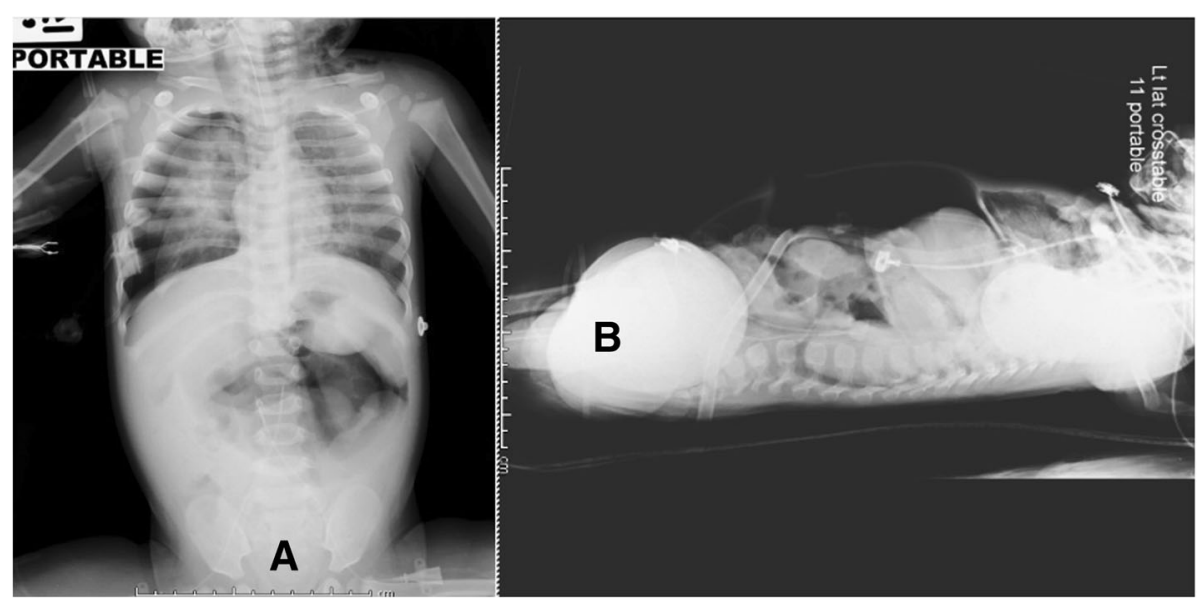

Fig. 1 A plain thoracoabdominal film showed pneumothorax, pneumomediastinum, and a tension pneumoperitoneum in anteroposterior (a) and lateral (b) view

no complication in the postoperative period. After 20 days in an intensive care unit, she was extubated and transferred to a pediatric ward. She was on oxygen therapy, on chest physical therapy, and kept hemodynamically stable until she had recovered. She was doing well at the time of 2-week interval follow-up. Currently, 12 months later, she is well without any sequelae from surgery.

\section{Discussion}

Pneumoperitoneum usually constitutes a surgical condition requiring intraabdominal repair of alimentary tract injuries. However, many cases of patients with nonsurgical pneumoperitoneum have been reported in the literature [1-6]. The condition affects patients of all ages and both genders. In the pediatric age group, neonates and infants were the most affected and almost all patients were involved with CMV. Barotrauma, generated by this type of ventilation, would be a cause of alveolar rupture. However, this generally results in pneumothorax, subcutaneous or interstitial emphysema, and pneumomediastinum [7-11]. Pneumoperitoneum related to mechanical ventilation is an unusual condition. The plausible mechanism would be increased pressure that causes bidirectional airflow, leaking along perivascular sheaths to the hilum and, rarely in some cases with pleuroperitoneal anatomical defects, dissecting to retroperitoneum $[5,11,12]$.

The patient described here was unusual in that severe barotrauma did not develop in a phase of support with CMV but occurred in the weaning phase of HFOV. HFOV is known to reduce air leakage in patients with poor lung compliance, particularly with pathology like ARDS. HFOV is considered a lung-protective strategy since it generates smaller tidal volume with high frequency and provides adequate ventilation with a relatively smaller pressure than CMV. Our patient developed pneumothorax and pneumoperitoneum on the seventh day of HFOV at mean airway pressure of 24 $\mathrm{mmHg}$ which was not a maximal mean airway pressure (32 $\mathrm{mmHg}$ ). In general, during HFOV support in patients with very low lung compliance, mean airway pressure underestimates mean alveolar pressure and will reflect the alveolar pressure when their condition of lung parenchyma improves [13-15]. Hence, our patient was affected with pneumoperitoneum at a low pressure of mean alveolar pressure.

There is a dilemma in the treatment of patients with spontaneous pneumoperitoneum. Many reported cases

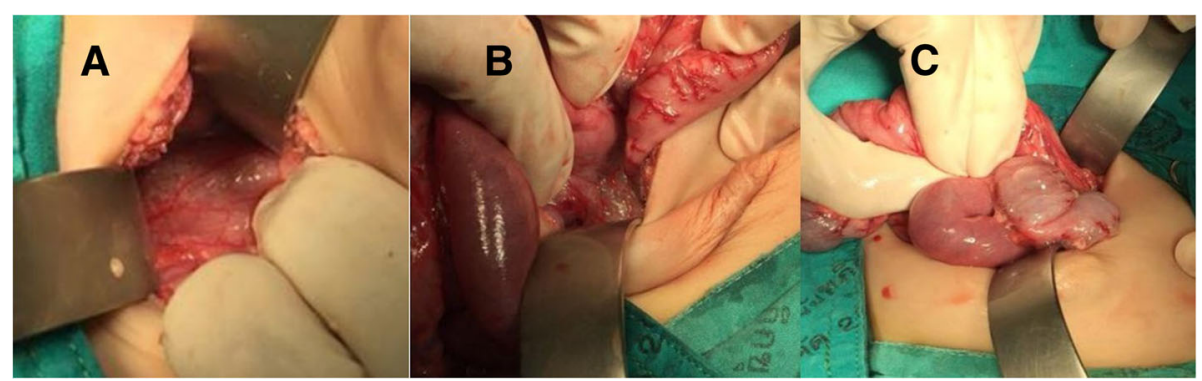

Fig. 2 Soft tissue emphysema was found in several places, including esophagogastric junction (a), mesenteric root (b), and terminal ileal serosa (c) 
could be safely treated with non-surgical treatment by an awareness of this condition [7, 16, 17]. Our patient possessed some risks factors of non-surgical pneumoperitoneum, including infant period, ARDS with ventilatory support, and signs of barotrauma, for example, pneumothorax, pneumomediastinum, and subcutaneous emphysema. Eventually, she underwent surgery not only because her vital signs continued to worsen, but also to exclude diaphragmatic injuries due to ICD, hollow viscus perforation, and abdominal compartment syndrome [5].

\section{Conclusions}

As we have shown, a case of tension pneumoperitoneum probably caused by HFOV was reported. Awareness of this condition should be included in the differential diagnosis. We suspected that the condition could occur in a patient supported with HFOV at a low pressure of mean alveolar pressure.

\section{Acknowledgements}

Not applicable.

\section{Authors' contributions}

PSu and SJ are the primary authority in the care of this patient. PSo is a surgeon who operated on this patient. PV helped to review this manuscript. All authors read and approved the final manuscript.

\section{Funding}

There is no financial relationship with any organization that sponsored this report.

\section{Availability of data and materials}

The authors have no material or software used in this report.

\section{Consent for publication}

This article does not contain any studies with human participants performed by any of the authors. The article was approved by our institutional review board (ECID, 14/2561). Written informed consent was obtained from the patient's legal guardian for publication of this case report and any accompanying images. A copy of the written consent is available for review by the Editor-in-Chief of this journal.

\section{Competing interests}

The authors declare that they have no competing interests.

\section{Author details}

'Department of Pediatrics, Panyananthaphikkhu Chonprathan Medical Center, Srinakharinwirot University, Nonthaburi 11120, Thailand. ${ }^{2}$ Department of Surgery, Panyananthaphikkhu Chonprathan Medical Center,

Srinakharinwirot University, 222 Tiwanon Road, Pak Kret, Nonthaburi 11120,

Thailand. ${ }^{3}$ Department of Surgery, Faculty of Medicine, Chulalongkorn

University, Bangkok 10330, Thailand.

Received: 23 November 2018 Accepted: 8 August 2019

Published online: 26 August 2019

\section{References}

1. Gupta R. Spontaneous Pneumoperitoneum in Pediatric Patients: Dilemmas in Management. J Indian Assoc Pediatr Surg. 2018;23:115-22.

2. Bedi NK, Chadha R, Bagga D, Dhar A, Malhotra CJ, Mohta A. Nonsurgical pneumoperitoneum in the newborn infant. Indian J Pediatr. 1991;58:867-73.

3. D'Agostino S, Fabbro MA, Musi L, Bozzola L. Pneumatosis cystoides intestinalis: a rare cause of nonsurgical pneumoperitoneum in an infant. J Pediatr Surg. 2000;35:1106-8.
4. Patel RV, Kumar H, Patwardhan N, Antao B. Pneumoperitoneum: a rare air leak in an infant with bronchiolitis and high-frequency oscillatory ventilation. BMJ Case Rep. 2013;2013.

5. García-Santos E, Puerto-Puerto A, Sánchez-García S, Ruescas-García FJ, Alberca-Páramo A, Martín-Fernández J. Abdominal compartment syndrome by tension pneumoperitoneum secondary to barotrauma. Presentation case. Cir Cir. 2015;83:429-32.

6. Schroder J. Spontaneous pneumoperitoneum in infants. Kinderarztl Prax. 1954;22:116-8.

7. Beilin B, Shulman DL, Weiss AT, Mogle P. Pneumoperitoneum as the presenting sign of pulmonary barotrauma during artificial ventilation. Intensive Care Med. 1986;12:49-51.

8. Boussarsar M, Thierry G, Jaber S, Roudot-Thoraval F, Lemaire F, Brochard L. Relationship between ventilatory settings and barotrauma in the acute respiratory distress syndrome. Intensive Care Med. 2002;28:406-13.

9. da Silva PS, de Aguiar VE, Fonseca MC. latrogenic pneumothorax in mechanically ventilated children: Incidence, risk factors and other outcomes. Heart Lung. 2015;44:238-42.

10. Hsu CW, Sun SF. latrogenic pneumothorax related to mechanical ventilation. World J Crit Care Med. 2014;3:8-14.

11. Ioannidis G, Lazaridis G, Baka S, Mpoukovinas I, Karavasilis V, Lampaki S, et al. Barotrauma and pneumothorax. J Thorac Dis. 2015;7(Suppl 1):S38-43.

12. Macklin MT, Macklin CC. Malignant interstitial emphysema of the lungs and mediastinum as an important occult complication in many respiratory diseases and other conditions: interpretation of the clinical literature in the light of laboratory experiment. Medicine. 1944;23:281-358.

13. Pérez Fontán JJ, Heldt GP, Gregory GA. Mean airway pressure and mean alveolar pressure during high-frequency jet ventilation in rabbits. J Appl Physiol. 1986;61:456-63.

14. Marini JJ, Ravenscraft SA. Mean airway pressure: physiologic determinants and clinical importance--Part 1: Physiologic determinants and measurements. Crit Care Med. 1992;20:1461-72.

15. Marini JJ, Ravenscraft SA. Mean airway pressure: physiologic determinants and clinical importance--Part 2: Clinical implications. Crit Care Med. 1992:20:1604-16.

16. Tallant C, Tallant A, Nirgiotis J, Meller J. Spontaneous pneumoperitoneum in pediatric patients: A case series. Int J Surg Case Rep. 2016;22:55-8.

17. Pisón-Chacón J, Pérez-Martínez A, Lecumberri García N, Armendáriz Cuevas Y, Molina Caballero A, Goñi Orayen C. An infant with intestinal pneumatosis and pneumoperitoneum: the difficult decision not to intervene. An Sist Sanit Navar. 2018;41:245-8.

\section{Publisher's Note}

Springer Nature remains neutral with regard to jurisdictional claims in published maps and institutional affiliations.
Ready to submit your research? Choose BMC and benefit from:

- fast, convenient online submission

- thorough peer review by experienced researchers in your field

- rapid publication on acceptance

- support for research data, including large and complex data types

- gold Open Access which fosters wider collaboration and increased citations

- maximum visibility for your research: over $100 \mathrm{M}$ website views per year

At BMC, research is always in progress.

Learn more biomedcentral.com/submissions 